\title{
Citation Patterns in Economics and Beyond
}

\author{
Matthias Aistleitner*, Jakob Kapeller** and Stefan \\ Steinerberger $^{* * *}$
}

\section{Working Paper 85}

\author{
November 2018
}

\begin{abstract}
In this paper we comparatively explore three claims concerning the disciplinary character of economics by means of citation analysis. The three claims under study are: (1) economics exhibits strong forms of institutional stratification and, as a byproduct, a rather pronounced internal hierarchy, (2) economists strongly conform to institutional incentives and (3) modern mainstream economics is a largely selfreferential intellectual project mostly inaccessible to disciplinary or paradigmatic outsiders. The validity of these claims is assessed by means of an interdisciplinary comparison of citation patterns aiming to identify peculiar characteristics of economic discourse. In doing so, we emphasize that citation data can always be interpreted in different ways, thereby focusing on the contrast between a 'cognitive' and an 'evaluative' approach towards citation data.
\end{abstract}

Keywords: citation patterns, economics, interdisciplinary, scientometrics, sociology of economics

JEL-Codes: A10, A12, A14

\footnotetext{
* Johannes Kepler University Linz, Institute for Comprehensive Analysis of the Economy (ICAE), matthias.aistleitner@jku.at

*** Johannes Kepler University Linz, Department of Economics and Institute for

Comprehensive Analysis of the Economy (ICAE), jakob.kapeller@jku.at

**** Yale University, Department of Mathematics, stefan.steinerberger@gmail.com
} 
The authors want to thank Chenglin Lu for excellent research assistance, Ernest Aigner and Florentin Glötzl for their generous provision of large-scale data on citations in economics and Vivienne Baldassare for her insightful comments. We also want to thank Matthew L. Wallace, Vincent Larivière and Yves Gingras for their kind provision of large-scale data on interdisciplinary citation behavior in economics and other disciplines. Financial support from the Institute for New Economic Thinking (INET) under grants INO1500038 \& INO1500039 (M.A. \& J.K.), from the National Science Foundation (NSF) under grant DMS-1763179 and the Sloan Foundation (both S.S.) is gratefully acknowledged.

This paper has been accepted for publication and will appear in Science in Context. 


\section{Introduction}

Scientometrics is the attempt to better understand the nature of scientific discourse by employing and analyzing quantitative data as it emerges from scientific exchanges (Mingers $\&$ Leydesdorff 2015). Analysis of citation data has achieved an especially prominent role, as it can not only be used to describe characteristic patterns within scientific conversations, but also serves as a means for assessing the impact and quality of contributions, outlets, authors or departments.

In this paper we take different ways of utilizing citation data as starting points to better understand the idiosyncratic character of the discipline of economics: more precisely, we compare citation patterns in economics to those of other academic disciplines and ask how different conceptual understandings of citation data also lead to differing interpretations with regard to the nature and comparative development of academic disciplines. Thereby we make use of two basic, but different, ways of interpreting citation data: on the one hand, we follow what is a standard routine in many academic contexts, namely to interpret citations as an indicator for the quality of the cited publication. We call this the evaluative use of citation data (see also Moed et al. 2012 and, for specific examples in economics, Arrow et al. 2011 and Diamond 1989). The second approach we suggest is to interpret the act of mentioning one scientific publication in another as an indicator for some form of 'communication' between researchers: in such an interpretation, the act of citing a paper is understood as a key element in scientific conversation. In such an approach citation analysis allows for assessing the properties of scientific conversation, which amounts to answering questions like 'who talks to whom', 'what are the intellectual foundations of a certain field of research' or 'how do scientists distribute their attention across the whole universe of scientific papers'? Such uses of citation data have traditionally been labeled as cognitive scientometrics (De Solla Price 1965; Rip \& Courtial 1984 and, for examples in economics, Hamermesh 2018 and Kim et al. 2006), which serves as a second and alternative frame of interpretation applied to our quantitative findings. While these two approaches are not necessarily contradictory - as citations often serve as both, a means for communication as well as an indicator of (dis)agreement, - they obviously emphasize different aspects of the scholarly process and, hence, can lead to quite different or even conflicting conclusions when applied to actual data.

In what follows we evaluate and compare citation data from five academic disciplines and analyze the respective citation patterns. We are especially interested in differences between citation patterns in economics and other disciplines, as economics is typically understood as a highly idiosyncratic field of research. There are several reasons for this peculiar character of economics: one such reason is that economists often consider their field as most advanced and, hence, superior compared to the other social sciences (e.g. Fourcade et al. 2015, Lazear 2000). This attitude is at least partly due to the origin-story of modern economics, which is influenced by the archetype of the natural sciences - a fact that had repercussions on both, the historical positioning of the discipline (Samuelson 1972) as well as the evolution of its prevailing practices (Mirowski 1989). Other aspects of the peculiarities of economics include differences in research style \& method (owing to a focus on mathematical and statistical methods; Morgan 1988), a stronger degree of internal stratification (Fourcade et al. 2015, Hodgson \& Rothman 1999), its prominent role in the context of political decision-making (Beker 2010, Hall 1989) or its focus on a single, major theoretical approach as summarized in highly standardized textbooks (Graupe 2016, Skousen 1997).

We take three of these alleged peculiarities of economics as a starting point for understanding interdisciplinary differences in citation patterns. Specifically, we relate to findings that (a) modern mainstream economics shows greater signs of stratification when compared to other fields of research (Bayer \& Rouse 2016; Fourcade et al. 2015; Han 2003; Hodgson \& Rothman 1999), (b) that economists are more prone to conform to institutional incentives due to their conceptual focus on instrumental rationality (Bauman \& Rose 2011; Etzioni 2015; Frank et al. 1993; 1996; Frey et al. 1993; Yezer et al. 1996) and (c) that mainstream economic research is largely autonomous in the sense that it only rarely relies on external input 
(Fourcade et al. 2015; Pieters \& Baumgartner 2002) and, hence, is largely inaccessible to paradigmatic or disciplinary outsiders (Dobusch \& Kapeller 2009, Fourcade et al. 2015, King 2003, Leijonhufvud 1973). We aim to provide an empirical evaluation of these claims on the peculiarity of economics by comparing citation patterns economics with those found in some companion social sciences (sociology, political science and psychology) as well as different branches of physics. The main rationale for selecting these fields is that they either cover related subjects and questions (the social sciences) or serve as a historically important conceptual archetype for conducting economic research and composing economic theory (physics). In doing so, we hope to shed some light on the question, whether and to what extent these peculiarities of economics are brought forth by a specific disciplinary culture as opposed to being driven by differences in research effort and quality.

Additionally we argue that economics is of special interest when it comes to questions of institutional power-relations, intellectual stratification or the distribution of attention within a discipline for at least two reasons: first, we not only find that the discipline of economics is characterized by stark internal differentiations and a rather rigid internal hierarchy, but also that these institutional properties affect several dimensions. Examples for this specifity include the popularity and gate-keeping power of specific outlets (Heckman \& Moktan 2018), the recruitment of officers and editors in the discipline's most important institutions (Fourcade et al. 2015), the high degree of institutional concentration in economic publishing (Aigner \& Glötzl, this issue) or the influence of PhD-advisers or co-authors from wellrespected institutions on publishing prospects (Colussi 2018, D'Ippoliti 2018).

Further we argue that the question of how attention, citations or resources are distributed is especially delicate in economics, as economics is typically understood as a paradigmatically and politically contested field of research (Lee \& Elsner 2011). This view in turn raises the question whether the alleged 'contestedness' of economics has an impact on its discursive properties, that is, in the way it organizes and reproduces scientific conversations. It is this backdrop of a strong degree of internal stratification in conjunction with the character of economics as a 'contested discipline' that motivated our main hypotheses on the peculiarity of economics and the economic discourse.

In what follows we analyze three main aspects of current economic discourse - disciplinary stratification, compliance with incentives and conceptual isolation - by means of an interdisciplinary comparison. Thereby, we expect our results to reflect the disciplinary character of economics: we assume to find higher degrees of discursive concentration, a higher responsiveness towards incentives and a greater propensity to engage in inwardlooking and exclusionary styles of research and discourse. However, while such findings would lend additional support to the diagnosis that economics is an exceptionally insular and hierarchical research field (Fourcade et al. 2015), we also hope to provide some clues on which factors - e.g. disciplinary culture, core theoretical ideas or paradigmatic prejudices do contribute to the emergence of these peculiarities of economics as an academic discipline. ${ }^{1}$

\section{Concentration}

In this section we subsume the comparatively high level of self-reference and the strongly hierarchical character of economics under the heading of concentration to signify that important authors, contributions, departments and outlets are (more) strongly concentrated in terms of their spatial distribution and personal as well as professional relations. We argue that one of the main roots of concentration in economics is the highly stratified tertiary education system comprised of a very small number of high-profile schools in economics, which in turn

\footnotetext{
${ }^{1}$ All data and code used in this paper is available from the author's website.
} 
have a tight grip on the most important outlets and professional associations ${ }^{2}$. The hierarchical structure within the economic discipline has been confirmed empirically in various ways. Medoff (2006), for instance, finds evidence of a "positive institutional Matthew effect" (Medoff 2006, 485) for Harvard University and the University of Chicago leading to a disproportionate amount of peer recognition devoted to contributions by economists affiliated with these institutions. On a more general level, Baghestanian \& Popov (2017) find a strong association between the reputation of an economists $\mathrm{PhD}$ granting institution and the probability of publishing in a top economic journal', which they call the 'Alma mater' effect:

"The Alma mater effect is large in size: a top 10 graduate has a $30 \%$ chance of publishing in a top 5 journal, but if instead he graduates from a top 30, his chances decrease to $17 \%$, and lowering his Alma Mater ranking further to $100+$ lowers his chances to 10\%." (Baghestanian \& Popov 2017, 17)

Another finding on 'concentration' in economics is due to Hodgson \& Rothman (1999) who analyze the institutional background and affiliation of the editors and authors of a set of thirty 'top' economic journals. They identify a strong dominance of institutions located in the U.S., and, within that subset, a dominance of a small group of elite universities. For instance, in 1995 more than half (54\%) of the authors of articles published in these 'top thirty' journals obtained their $\mathrm{PhD}$ at one of twelve prestigious U.S. universities ${ }^{4}$, while at the same time more than one fifth $(21 \%)$ of authors in said journals were also affiliated with one of these universities.

A partial replication of the analysis of Hodgson \& Rothmann (1999) with data from 2014 suggests that this level of "institutional oligopoly" has remained fairly constant over time: Just looking at the subsample consisting of three major journals, the Quarterly Journal of Economics (QJE), the American Economic Review (AER) ${ }^{5}$ and the Journal of Political Economy (JPE) reveals that a majority of authors (55\%) publishing in these outlets received their $\mathrm{PhD}$ at one of the twelve universities mentioned above. In 2014, more than one third $(38 \%)$ of these authors were affiliated with one of these universities at the time of publication (see also Wu 2007).

Similar tendencies of concentration can also be found in large-scale analyses of the economic literature. Laband (2013), for instance, analyzes the representation of journals in the reference sections of the 409 most cited economics papers published between 2001-2005: more than half $(55 \%)$ of the references cited by these top-papers came from a group of only twenty journals. Even more strikingly, the proportion of citations devoted to the three journals mentioned above - QJE, JPE and AER - is about one fifth (20.6\%) of the total references (cf. Laband 2013, F250-F251). Against this backdrop, it comes as no surprise that a recent analysis of the development of economic 'top-journals', which has been published in the Journal of Economic Literature, was limited to the study of only five journals (adding

\footnotetext{
${ }^{2}$ For example, the prestigious economics departments at the University of Chicago and Harvard University both publish also high regarded journals in the profession, the Journal of Political Economy (JPE) and the Quarterly Journal of Economics (QJE). Three further high-profile outlets, the American Economic Review (AER), the Journal of Economic Literature (JEL), and the Journal of Economic Perspectives (JEP) are published by the leading professional organization in the field, the American Economic Association (AEA). Within the AEA Leadership, in turn, also a clear dominance of economists affiliated with one of those departments can be observed: A closer look at the past presidents of the AEA (1886-2016) reveals that a third of them were affiliated with either the University of Chicago or Harvard University (a further quarter at least with one of four other prestigious U.S. universities: Princeton University, Yale University, M.I.T., and Stanford University) (data retrieved from aeaweb.org). These short examples do not only indicate the dominant position of a specific set of actors, but also shows how prestigious universities, important associations and major journals in economics are institutionally intertwined.

${ }^{3}$ Additionally they find, that “'in-house' journals favor 'in-house' graduates” (Baghestanian \& Popov 2017, 17) which obviously leads to a further reinforcement of the stratification mentioned above.

${ }^{4}$ The respective universities are: Harvard University, M.I.T., University of Chicago, Stanford University, University of Michigan, University of California Berkeley, Princeton University, Yale University, University of Wisconsin, Columbia University, University of Pennsylvania, and Northwestern University (Hodgson \& Rothman 1999, F173)

${ }^{5}$ For a more detailed analysis of the AER authorship see Torgler \& Piatti (2013).
} 
Econometrica and the Review of Economic Studies to the set of three journals mentioned above; see Card \& DellaVigna 2013).

Our empirical application takes a closer look at the 'Big 5', i.e. the five core journals covered by Card \& DellaVigna (2013), to gain potential insights on tendencies of concentration within economic discourse similar to those already observed in the context of editor and authorships in top-journals (Hodgson \& Rothman 1999) or the recruitment of officers for academic associations (Fourcade et al. 2015). Specifically, we measure the concentration of attention within top-journals by assessing the degree of self-referentiality within this group of journals to compare the relative openness of top-journals across fields. Figure 1 plots the share of journal self-citations as well as the share of citation flows originating from within the 'Big 5' relative to total citations in these journals for the period 2009-2013. Figure 1 conveys our first finding: more than a quarter of all sources cited by the top five economic journals originate are self-referential - they stem from the very same set of journals.

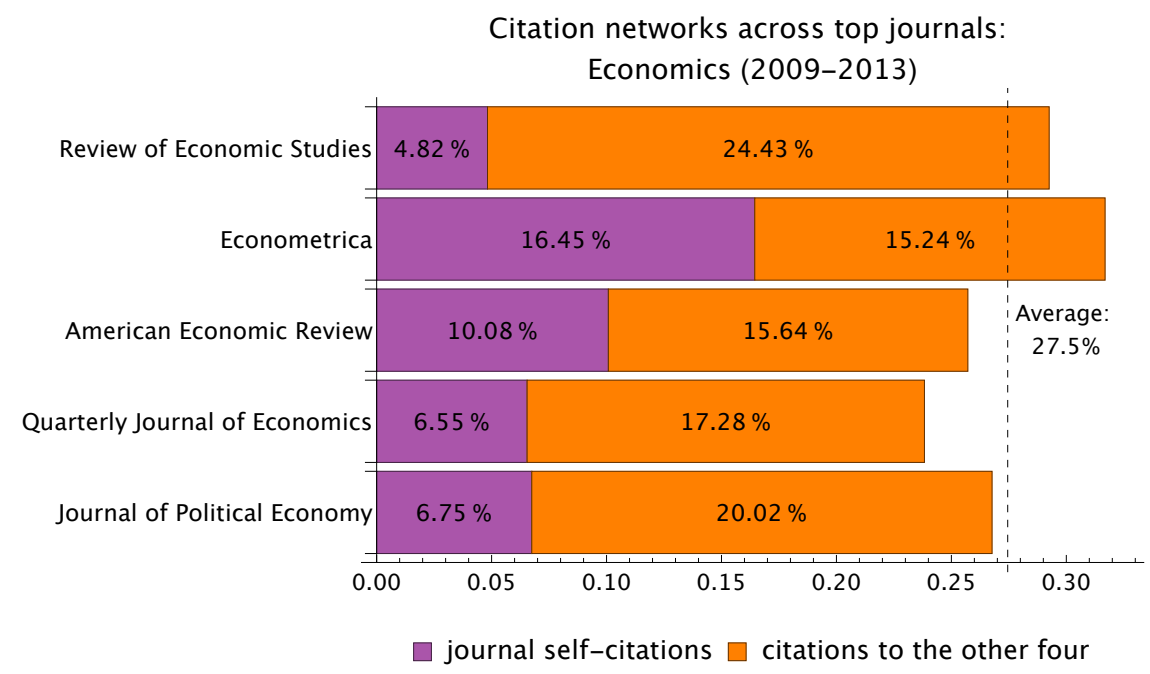

Figure 1: The intra-group citation behavior of five core economic journals (authors' own calculation based on data from Clarivate Analytics).

In addition to this key observation - that one out of four citations made in this journal sample also originates from within this sample - it can also be inferred from Figure 1, that the average share of self-citations within a top-journal plus the share of citations imported from its four 'best buddies' is fairly stable across the top five journals with individual values ranging from $23.8 \%$ (QJE) to $31.7 \%$ (EMA).

When comparing the citation pattern found across economics' top journals to the degree of self-reference in top journals located in other fields - e.g. the 'top five' journals in psychology, sociology, political science and physics (Figure 2) - there is the difficulty of selecting appropriate sets of top journals for these fields to advance a sensible comparison across disciplines. To enhance comparability of the respective 'top' samples in each discipline we first harmonized our selection criteria across all fields under study. Specifically, we selected every journal, which was ranked in the top 20 of Clarivate Analytics ${ }^{16}$ annually published Journal Citation Reports (JCR) for ten consecutive years (2006-2015) to account for the relative long-term position of outlets - a condition inspired by the ranking patterns in economics, where the 'Big 5' are constantly within the Top 20 of journals as ranked by the JCR. In the case that more than five journals fit those criteria, the five journals with the highest average rank were selected.

\footnotetext{
${ }^{6}$ Before 2016, the JCRs were published by Thomson Reuters.
} 

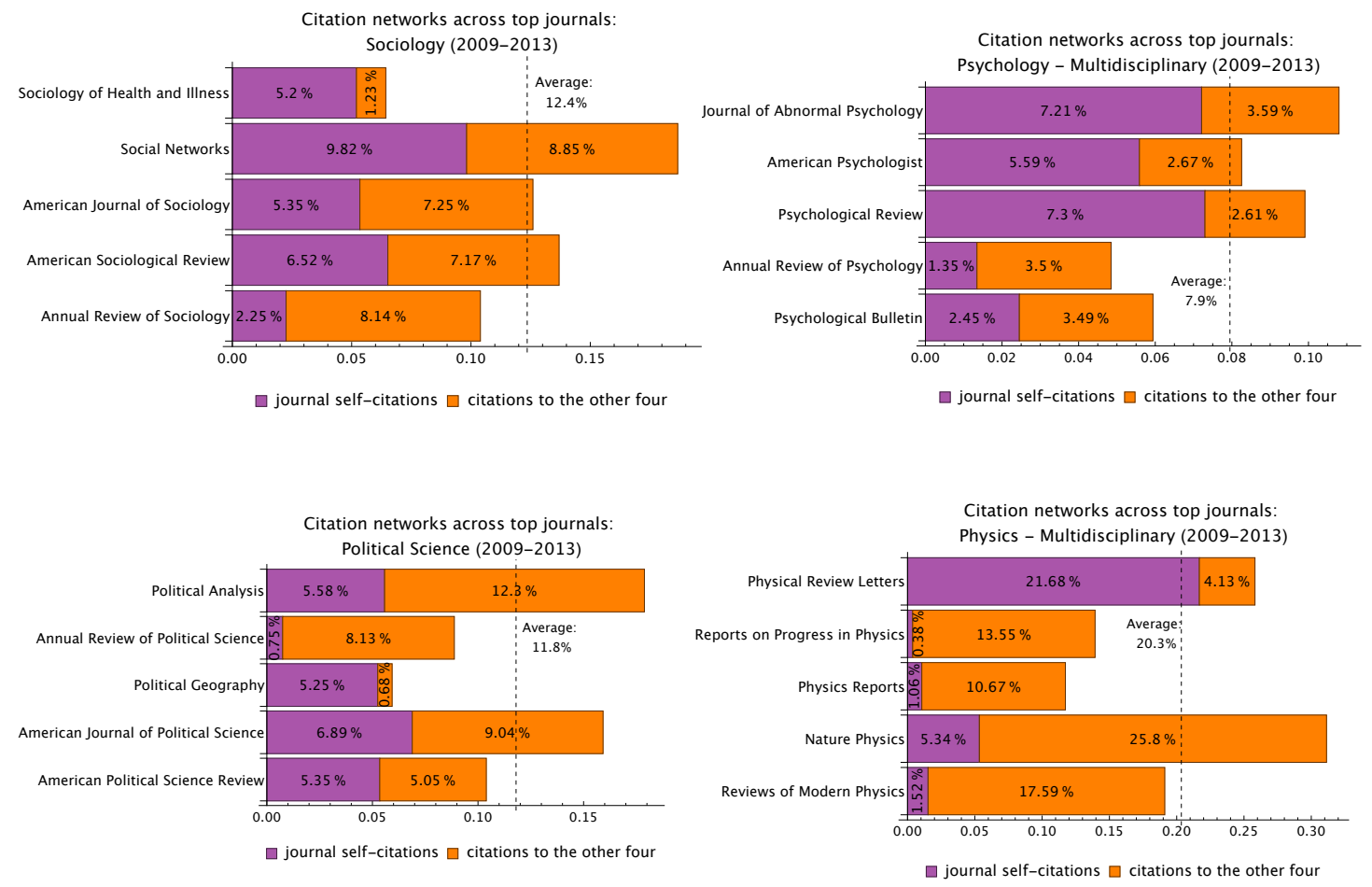

Figure 2: An interdisciplinary comparison on concentration - the intra-group citation behavior of five core journals in psychology (multidisciplinary), sociology, political science, and physics (multidisciplinary) (authors' own calculation based on data from Clarivate Analytics).

In comparison with Figure 1 the results shown in Figure 2 reveal two remarkable findings. Firstly, in the other social science disciplines considered here the degree of concentration measured as the share of journal self-citations plus the citation flow within top journals is with average values ranging between $7.9 \%$ and $12.4 \%$ of total citations - pending between a third and a half of what we found for economics $(27.5 \%)$. This finding reinforces the diagnosis that economics exhibits a much more pronounced hierarchy, or "pecking-order" (Leijonhufvud 1973, 328), compared to other social science disciplines. Secondly, this relative high degree of concentration in economics also exceeds the degree of concentration measured within our sample of (multidisciplinary) physics journals (20.3\%). Hence, although the difference between economics and physics as its conceptual archetype is less pronounced than the one between economics and the other social sciences, there remains a substantial gap even in comparison to the much different and often more narrow discourses in the realm of the natural sciences.

In response to the finding on concentration in physics documented in Figure 2, we acquired data for analyzing a second example in the realm of physics, but, this time, focusing on top journals in very specific research areas to assess the intuition that economics is similar to specialized, instead of general, discourses in physics. In doing so, we found a striking similarity between our novel sample from physics consisting of specifically chosen field journals (Physical Review A-E, see Figure 3) and economics. Although the network structures differ markedly between these two cases - the Physical Reviews are huge journals with an average publication output of more than 3.000 papers/year focusing on very different subfields, the degree of concentration is nearly as high (27.3\%) as in the economics sample. While the stronger content-based separation of the respective journals into subfields 
(designated with letters $A-E^{7}$ ) provides an explanation for much higher share of self-citations, we also find that the average amount of self-citations within these journals (24.1\%) is eventually rather close to the average share of attention the 'Big 5 ' in economics devote to themselves $(27.5 \%)$. In sum, the top five journals in economics taken together behave rather similar to specific field journals within physics in terms of discursive concentration.

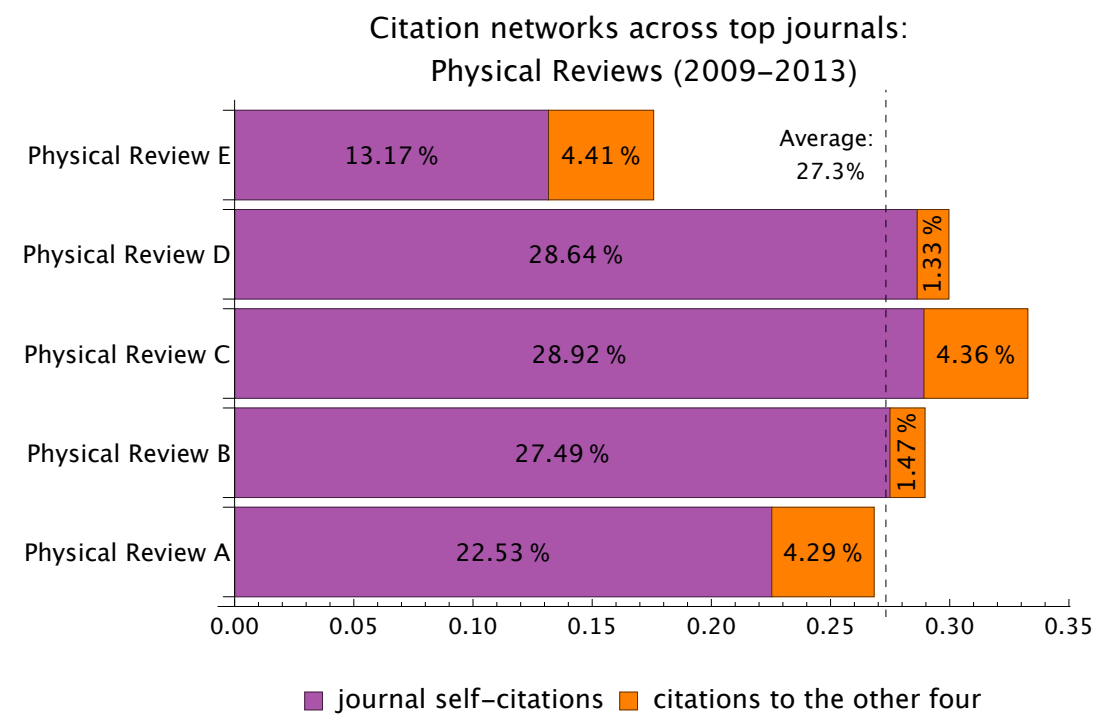

Figure 3: Citation patterns in specialized physics journals - the intra-group citation behavior of five core field journals in physics (authors' own calculation based on data from Clarivate Analytics).

The result that the 'Big 5' in economics behave similar to more specialized subfields in physics and exhibit correspondingly high rates of concentration is especially striking in the face of an overall decrease in the concentration of cited sources within the academic literature over the past decades (Larivière et al. 2009). Beside this anachronism, it is quite remarkable that a multi-faceted discipline such as economics, which deals with mathematical, gametheoretical, sociological, historical, philosophical and psychological components, behaves in the same concentrated manner as, say, Physical Review B, which focuses on condensed matter and material physics. The fact that the relative citation patterns of top multidisciplinary journals in physics (as documented in the lower right panel of Figure 2) shows much less regularity and, hence, gives an indication for the tight conceptual and theoretical commitments established in contemporary economics.

While these findings are interesting in themselves, it is worthwhile to further explore how their actual implications depend on the respective frame of reference: in terms of an evaluative interpretation, for instance, the relevant problem is to explain the comparatively strong agglomeration of high-quality articles in such a small number of outlets. A potential conclusion to be drawn from this perspective is that the editors of these journals do excellent work and manage to concentrate most high-quality research in economics in their outlets. This constellation, in turn, makes it easier to locate said contributions. In contrast, while a cognitive interpretation could take such reasoning into account it would eventually be forced to ask a broader set of questions and inspect other variables, like the diversity of authors, readers and institutional backgrounds, the role of reputational concerns or the impact of 'Big 5' publications on tenure decisions and related career concerns (Heckman \& Moktan 2018).

\footnotetext{
${ }^{7}$ The respective letters stand for specific research fields in physics: (A) atomic, molecular, and optical physics and quantum information, (B) condensed matter physics, materials physics, (C) nuclear physics, (D) particles, fields, gravitation, and cosmology, and (E) statistical, nonlinear, biological, and soft matter physics.
} 
In comparison with physics (Figure 3) such a cognitive perspective would necessarily go beyond asserting that economics editors are simply superior, but rather ask which properties make economics discursively similar to subfields in modern physics.

Under such premises the outcome looks quite different: here the findings above reveal that the economic discourse at the very top is to a large extent self-contained and exhibits a strong hierarchical character while the discourse in sociology and political science can be characterized as more diverse and, correspondingly, less hierarchical and insular. This example illustrates how the interpretation and associated valuation of citations is guided by theoretical presumptions, which effectively decide how to translate numerical into verbal assessments.

\section{Reactivity}

The second factor we examine in this paper relates to the phenomenon of reactivity, specifically in connection with scientific research evaluation. Our basic argument is that the introduction of journal rankings in economics in particular and in academia in general has led to a change in and a refinement of the institutional incentives governing the academic sphere. Notwithstanding the fact that rankings have a long tradition in economics (see, for instance, Diamond 1989; Fusfeld 1956; Graves et al. 1982; Liebowitz \& Palmer 1984; or the rankings hosted by RePEc on repec.org), we argue that the importance of journal rankings received a significant boost within the last two decades (see also Kalaitzidakis et al. 2011; Stern 2013; Zimmermann 2013). The journal rankings originally produced by the Institute for Scientific Information (ISI), whose database is today widely known as Clarivate Analytics' Web of Science, proved to be pivotal for the ascension of journal rankings in academic assessment and evaluation, which eventually led to visible changes in the disciplinary trajectory of economics at the national level (Lee 2007; Bloch 2010; Corsi et al. 2010). As these rankings are imposed onto the scientific field for means of assessment and evaluations of researchers and institutions they do not come without an impact on the institutional incentives individual researchers face.

"There is a powerful feedback between the ranking systems used to assess scientific productivity and the actions of scientists trying to further their careers via these ranking systems." (Braun et al. 2010, 871)

In short, the introduction of journal rankings for purposes of evaluation causes reactive behavior invoked by the 'authority of numbers'.

"Casting reactivity as a threat to validity of measures draws attention to the dynamic nature of quantitative authority and its capacity to intervene, sometimes dramatically, with other forms of authority." (Espeland \& Sauder 2007, 6-7)

The notion of reactivity is a well-known concept in the methodology of the social sciences and refers to instances, in which the application of some instrument of investigation triggers a change in the behavior of the investigated subjects or institutions. Such behavioral changes are conceived as a source of bias, which may arise in the course of data-acquisition (especially in circumstances, where data is collected repeatedly). While it is methodologically correct to speak of a bias here in the sense that such a behavioral change is to be considered as an artifact created in the course of observation, it seems important to note that the change in behavior is, eventually, real: although induced by external observation, such changes in behavior can be profound and have far-reaching effects.

In the case of methodologically guided evaluations in general and evaluative scientometrics in particular, reactivity induces actors to anticipate evaluation criteria. This anticipation in turn affects the behavior of the subjects or institutions evaluated according to these criteria (Ferraro et al. 2005, Ghoshal 2005). Such forms of 'evaluation bias' have been confirmed 
empirically, especially for evaluation procedures such as rankings, where Espeland \& Sauder's (2007) seminal study on the reactivity in the context of the US News' law school rankings stands out (see also Rafols et al. 2012; Willmott 2011). Another prominent example of ranking-induced reactivity is the so called ease of doing business country-ranking developed by the World Bank, which also induces reactive behavior of government institutions in favor of the defined ranking criteria.

"The main message is that many countries may find it easier to change their ranking in 'Doing Business' than changing the underlying business environment." (Høyland et al. 2008, 12)

Against this backdrop, it does not come as a surprise that journal rankings do trigger similar effects when used for large-scale institutional evaluation: Italy, for instance, has recently introduced a quantitative standard for supporting decisions on appointment and promotion within the academic system. While the official purpose of this reform is to serve as an objective way to decrease the amount of nepotism in hiring, one cornerstone is the number of scientific publications as indexed by either Scopus or Web of Science. This has led to various attempts of Italian scholars to have past publications that are not covered by Scopus/WoS included into Scopus/WoS and created strong incentive to only publish in journals covered by these two indices (Abatemarco \& Dell'Anno 2012). While we observe an overall "climate of perverse incentives" (Edwards \& Roy 2017, 51) and also more blunt forms of reactivity taking the form of simple gaming strategies in academia (Kapeller 2010; Wilhite \& Fong 2012; Necker 2014), in this paper we want to ask a more nuanced question: how would the introduction of journal rankings and their rise to institutional authority change existing patterns of scientific recognition to impact citation behavior in economics? Taking the classic Mertonian view (1968) that future recognition depends on past recognition (see also Haucap \& Muck 2015), we argue that the introduction of journal rankings as evaluative devices affects the self-reinforcing routines governing the distribution of academic attention by raising the relative importance of journals as compared to specific authors or contributions. As journals gain in visibility in the course of the introduction and utilization of journal rankings, some attention is redistributed from the actual producers and products of scientific activities to their (most important) outlets. And, indeed, Attema et al. $(2014,495)$ claim to have found, that U.S. economists "would sacrifice more than half a thumb for an AER publication."

So far, we have introduced two hypotheses on reactivity, namely that the introduction of journal rankings redistributes prestige in the favor of journals (see also Mcdonald \& Kam 2007; Lariviére \& Gingras 2010) and that economists intuitively and/or deliberately consider this redistribution of prestige, which eventually leads to a change in recorded citation patterns. Specifically, our theoretical argument implies that we should see the share of citations received by the top fraction of articles within a top journal decrease, while the share of citations going to the least considered fraction of papers is expected to rise as all papers in a given outlet draw on the latter's prestige (see Figure 4 for a stylized illustration of the expected effect). 


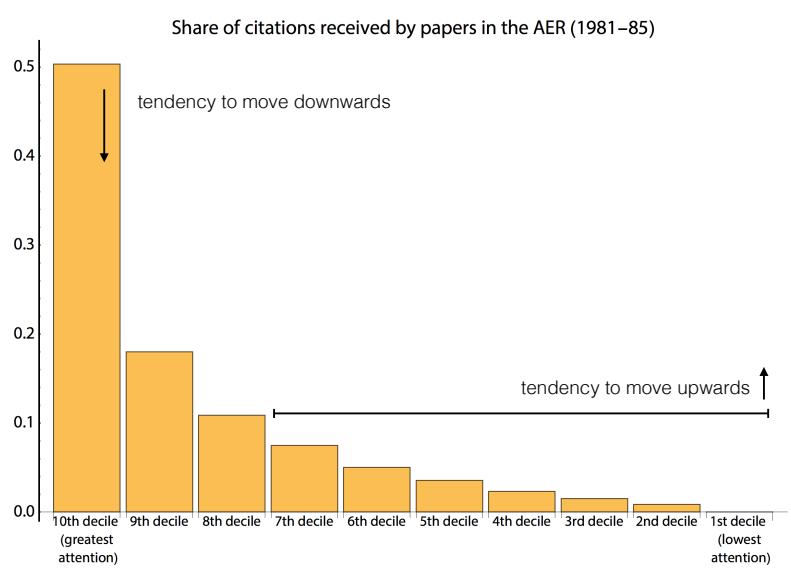

Figure 4: Expected effect of a relative increase in journals' prestige on observed citation patterns.

We would assume to find effects as envisaged in Figure 4 - an increase in the share of the bottom two thirds of articles with a corresponding decrease in the share of top-cited papers across all disciplines. However, we also expect these effects to be most pronounced in economics as we assume a higher degree of conformity to institutional incentives in economics as compared to other fields.

In what follows, Figures 5 to 7 show our empirical findings on this question. In acquiring these results we analyzed the citation history of all (top-) journals sampled so far $^{8}$ and further extended our sample by acquiring corresponding data for Nature and Science. More specifically, we compare the distribution of citations to papers published between 1981 and 1985 (counting received citations till 1990) to the distribution of citations to all articles published between 2004 and 2008 (counting citations till 2013) for all analyzed journals to identify changes in aggregate citation patterns.

Figure 5 shows the results so obtained by providing individual estimates for all disciplines under study. The resulting pattern is in close correspondence with our theoretical expectations - a decrease in the share of citations dedicated to the upper limit of the distribution is complemented by a corresponding increase in lower deciles. The discipline of economics indeed shows the biggest effect with an effective decline in the share of the top decile of papers by roughly 9\%. Only the generalist top journals Science and Nature (as shown in Figure 6) as well as top journals in psychology come close to this pattern, while the same effect for the other social science journals - as well as the physics journals under study - is much less pronounced.

\footnotetext{
${ }^{8}$ Due to some minor data limitations (data for the 1980s does not exist for Sociology of Health and Illness, Political Geography, Annual Review of Political Science, Political Analysis, Nature Physics, and Physical Review E) only 24 of the 30 journals discussed in section 2 enter this analysis.
} 
Figure 5: Change of citation patterns in top journals: 1980s vs. today (authors' own graph based on data from Clarivate Analytics)

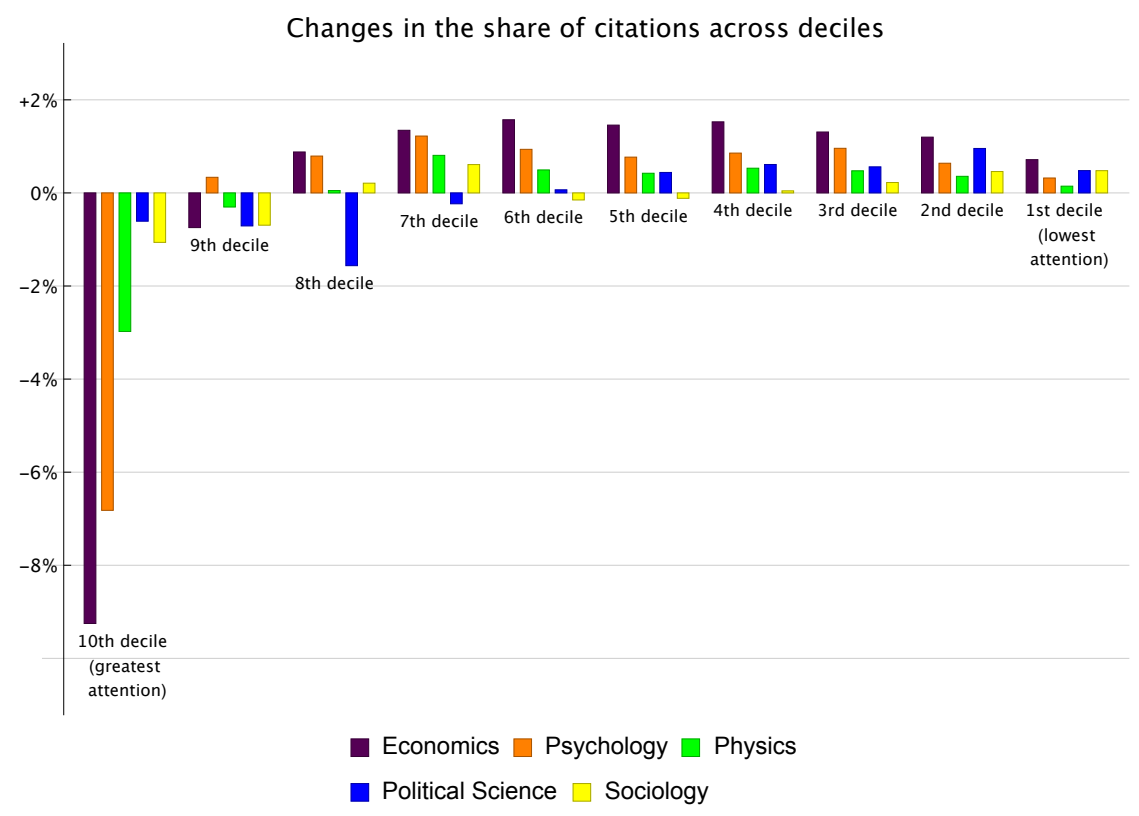

Figures 6 provides a different perspective on the same data by further aggregating results across disciplines: it shows, that the expected pattern is much more pronounced in economics as compared to the average social science or physics paper in our sample. Indeed, the journals coming closest to the pattern found for economics are multidisciplinary journals, which enjoy a high visibility and, hence, command a considerable amount of prestige. Thus, it seems that in terms of reactivity induced by journal prestige, economics really plays in the league of the world's most prolific journals, while leaving the mundane world of ordinary research well behind.

Changes in the share of citations across deciles:

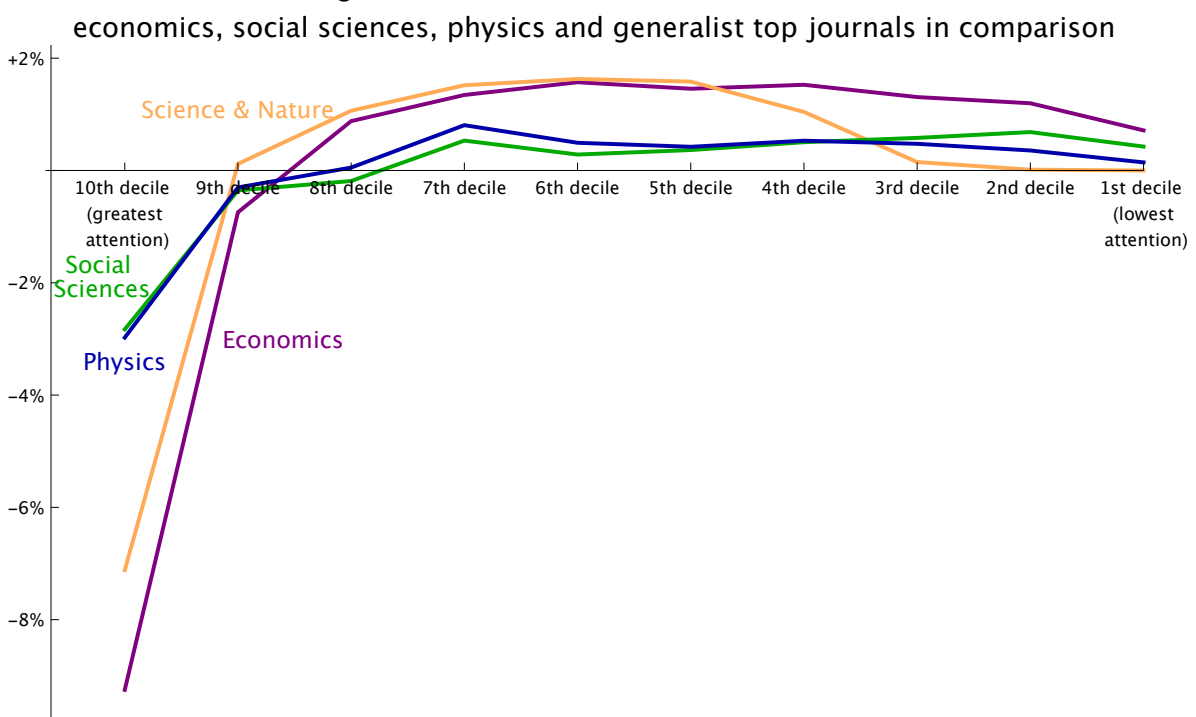

Figure 6: Citation patterns in the 1980s and today: An aggregated comparison (authors' own graph based on data from Clarivate Analytics). 
Eventually, the question is what to make of this result? Although the alignment between expected citation behavior and actual patterns retrieved is close and the supposed pattern nontrivial, how can we assure that our inter-temporal comparisons are due to the role of journal rankings and not, let's say, due to other factors, like different research cultures ${ }^{9}$ or simply the rising size of the academic literature in general? While such alternative explanations are indeed appealing and, at the same time, the possibilities to quantitatively assess qualitative differences across fields are limited, we can confront the most obvious argument in this context, namely the growth of the academic literature in general. Figure 7 compares the overall output of scientific publications between the two periods, which has increased significantly in all disciplines under consideration. However, the similarity between the citation patterns in economics and the multidisciplinary journals shown in Figure 6 stands here somewhat in contrast to different growth rates in these disciplines $(+187 \%$ in economics vs. $+51 \%$ in multidisciplinary sciences). Conversely, the two remaining disciplines, which experience growth rates more similar to economics $(+88 \%$ in the social sciences and $+103 \%$ in physics), but differ fundamentally in terms of absolute numbers, both exhibit a similar citation pattern (see again Figure 6). This pattern is, in turn, quite different to the one in economics. As this comparison is inconclusive, it can hardly be argued that the specific differences noted in Figures 5 and 6 are solely due to the different growth rates affecting these fields.

Changes in the publication output in different fields

$\square$ 1981-1990 $\square$ 2004-2013

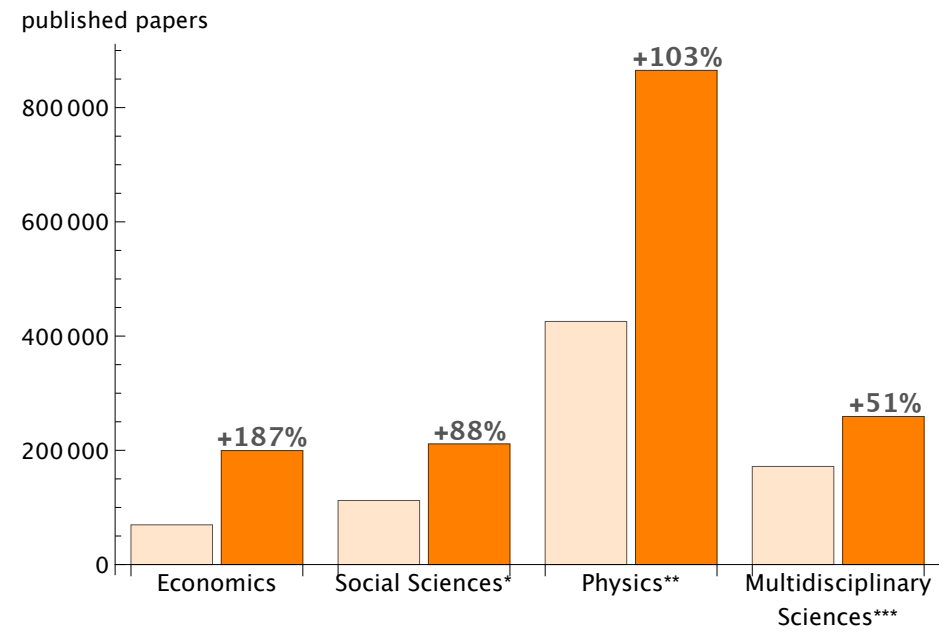

Figure 7: Publication output in the 1980s and today: An aggregated comparison. Authors' own graph based on data from Clarivate Analytics.

Note: Published document types such as editorials, book reviews, bibliographies or biographic items were excluded in this analysis.

*Includes sociology, political science and psychology (multidisciplinary).

**Includes physics multidisciplinary, physics nuclear, physics atomic molecular chemical, physics condensed matter, and physics particles fields.

***The Web of Science Category 'Multidisciplinary Sciences' includes journals that cover a broad spectrum of different specialties such as PLOS ONE, PNAS, Nature, Science etc.... The overlap with other categories (e.g. social sciences, physics) is marginal in both periods $(8.1 \%$ and $3.1 \%$ of all papers respectively).

\footnotetext{
${ }^{9}$ For example, Tsay (2009) analyzes scientometric data between journals of physics, chemistry and engineering and finds some evidence for differences in citation behavior among scientists in these disciplines, although this comparison is restricted to a period of one year (2002).
} 
While our argument - that the difference in responsiveness to incentives across disciplines contributes to the differences in citation patterns - is surely of a cognitive origin, an evaluative approach to scientometrics would be able to offer several alternative explanations. For instance, one could argue that the average quality of papers in top journals has increased more strongly over time than the quality of top-cited papers in these journals - and that the very same process is going on faster in economics than in other fields. Again, the interpretation of the observed empirical patterns depends on our preferred theoretical framing as the data hardly put us in an appropriate position to assess the relative merits and weaknesses of a particular perspective.

\section{Diversity}

Our final section deals with an alleged lack of diversity in economics. Diversity is a concept that can be approached from a variety of angles, as, for instance, demographic, disciplinary or theoretical diversity. While a lack of diversity in terms of demography is well documented in economics (e.g. Bayer \& Rouse 2016), Fourcade et al. (2015) recently studied the matter of intellectual diversity in economics from a disciplinary angle. By analyzing both attitudes towards interdisciplinary research as well as interdisciplinary citation patterns in economics, sociology and political science, Fourcade et al. (2015) show that economists are comparatively less inclined to import findings from other disciplines and also have less trust towards interdisciplinary approaches and research strategies. These findings are highly consistent with past results from data-driven research on citation patterns, which document the solitary character of economics in terms of disciplinary location and age of imported references. Relative to other disciplines from the natural and the social sciences, papers in economics refer with a higher probability to their own specialty (see Figure 8) and are, on average, older than papers cited in other disciplinary contexts (Wallace et al. 2012). The only discipline in our data exhibiting a higher degree of self-referentiality than economics astrophysics \& astronomy - is coined by a very specific and clearly separable research focus ('outer space'), which may explain the high share of inward-looking citations in this field. ${ }^{10}$ For economics, on the other hand, these results not only point to the comparatively strong imprint of traditional approaches and findings on current research, but also signify comparatively strong intellectual autarky in current economic discourse.

\footnotetext{
${ }^{10}$ We want to thank Vivienne Baldassare, Yale Astronomy, for sharing her experience and intuition, which helped us to solidify our interpretation of the result for the astronomy/astrophysics category.
} 
The degree of 'self-referentiality':

a large scale sample for several disciplines

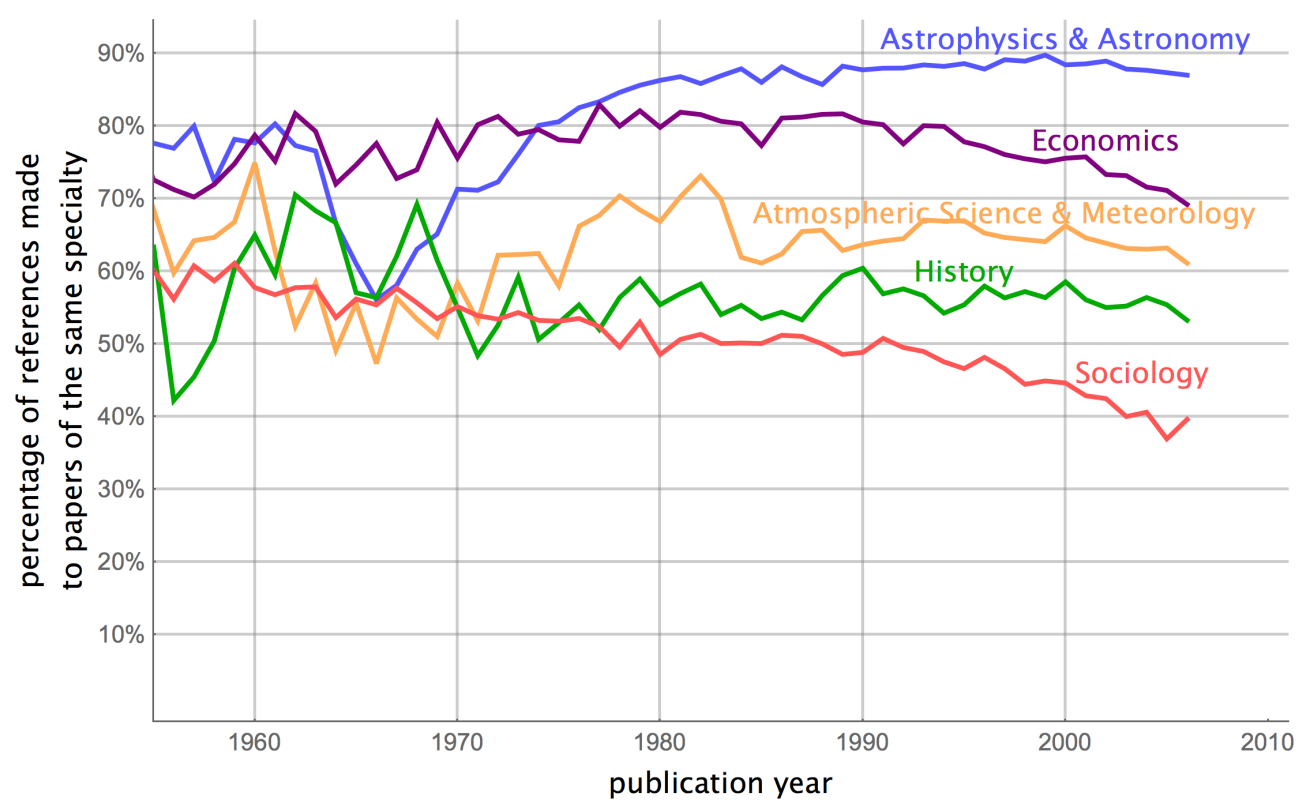

Figure 8: Citation patterns in economics and other disciplines: a large scale sample. Authors' own graph based on data from Wallace et al. (2012) ${ }^{11}$.

Against this backdrop it does not come as a surprise, that Fourcade et al. (2015) also summarized their findings under the heading of 'insularity' to signal an absence of theoretical and conceptual diversity. And indeed, economists often conceive interdisciplinary interaction as a competition rather than cooperation, where disciplines are to be judged with regard to their relative 'performance'.

"What is interesting to think about are the terms of trade between economics and all these other disciplines. We are clearly a net exporter to political science and sociology." (Wolfers 2010, 30)

In what follows, we want to add to this picture by supplying a perspective on conceptual diversity in economics. This question is especially peculiar as economics can be regarded as a 'contested discipline' (Lee \& Cronin 2010, Lee \& Elsner 2011). The character of scientific discourse in economics differs from that found in other social sciences, because economics is dominated by a single paradigm - neoclassical economic theory - which significantly shapes academic teaching and economic research. ${ }^{12}$ The resulting exclusion of alternative economic approaches, like institutional microeconomics, evolutionary analysis of economic change or Keynesian macroeconomics, from the 'official' economic discourse led to the foundation of nowadays eminent - heterodox economic journals, like the Cambridge Journal of Economics, the Journal of Post Keynesian Economics or the Journal of Economic Issues in the late 1960s and 1970s (King 2003, 134-136). Notwithstanding these efforts for providing alternative economic approaches with adequate institutional foundations, alternative or 'heterodox' schools of thought nowadays only constitute a small fraction of the economics discipline. While heterodox economists are confronted with a series of exclusionary practices and routines (Dobusch \& Kapeller 2009, King 2013) their works also draw on a broader variety of sources and inputs and, hence, exhibits a distinctive, more interdisciplinary communicative

\footnotetext{
${ }^{11}$ We are grateful to Matthew L. Wallace, Vincent Larivière and Yves Gingras for providing the large-scale data necessary to build this figure.

${ }^{12}$ We recommend Backhouse (2005) or Dobusch \& Kapeller (2009) for a discussion of the historical roots of this paradigmatic dominance.
} 
pattern (Glötzl \& Aigner 2015). Moreover, Glötzl \& Aigner (2015) provide additional evidence for this contestedness of economics by pointing to a 'mainstream core - heterodox periphery structure' (see also: Dobusch \& Kapeller 2012a) in the citation networks associated with different economics departments at the University of Vienna and the Vienna University of Economics and Business, that differ with respect to their openness for alternative and heterodox approaches in economics.

The resulting lack of diversity within the economic discipline has been studied empirically, in particular by analyzing the relative citation flows between 13 high-ranked mainstream and 13 high-ranked heterodox economic journals in two different periods: before (1989-2008; Dobusch \& Kapeller 2012b) and after the recent financial and economic crisis (2009-2013; Aistleitner et al. 2018). The results indicate that the monistic and closed citation behavior exhibited by (highly-ranked) mainstream economic journals remained stable after the crisis, as the mainstream journals continue to devote only minimal attention to heterodox inputs (as is evidenced by the small share of citations - less than $3 \%$ - imported from heterodox sources $^{13}$; see Figure 9). On the contrary, the heterodox journals themselves exhibit a more balanced citation pattern with import shares from the mainstream sample of $47.6 \%$ (precrisis) and $24.6 \%$ (post-crisis). In the context of the crisis, this result lends support to Kuhn's (1962) prediction, that a dominant paradigm that faces a significant anomaly (the crisis) will strive for adapting already established theses, models and methods instead of turning to more fundamental revisions.

To further assess the robustness of these results, Figure 9 additionally shows results derived from data on a control group and on a large-scale sample. The first robustness-check uses a control group to ask whether the comparative neglect of heterodox inputs in mainstream outlets can be explained by the lower ranks of heterodox journals, which supposedly signify a lower overall quality. In composing the control group we used a group of mainstream journals with similar ranking positions than the heterodox sample. The second robustness check analyzes data of a large-scale sample acquired from the Web of Science database to scrutinize the robustness of the observed differences.
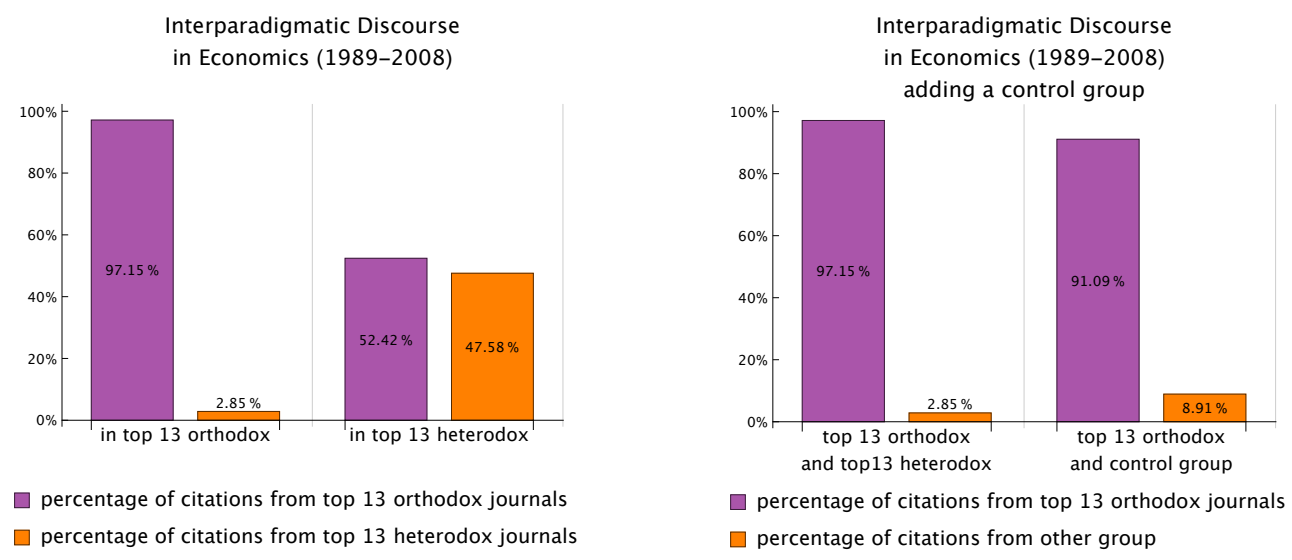

\footnotetext{
${ }^{13}$ A more detailed analysis of the data from 1989-2008 furthermore shows that the percentage of citations from the top thirteen heterodox journals exported into mainstream journal literature considered here $(2.85 \%$ of total references $)$ is driven heavily by statistical outliers: about $80 \%$ of these references are caused by only three journals that hold a special position within the economic discourse: On the heterodox side of the sample, the Journal of Economic Behavior and Organization, on the mainstream side of the sample, the Journal of Economic Geography and Economic Geography.
} 

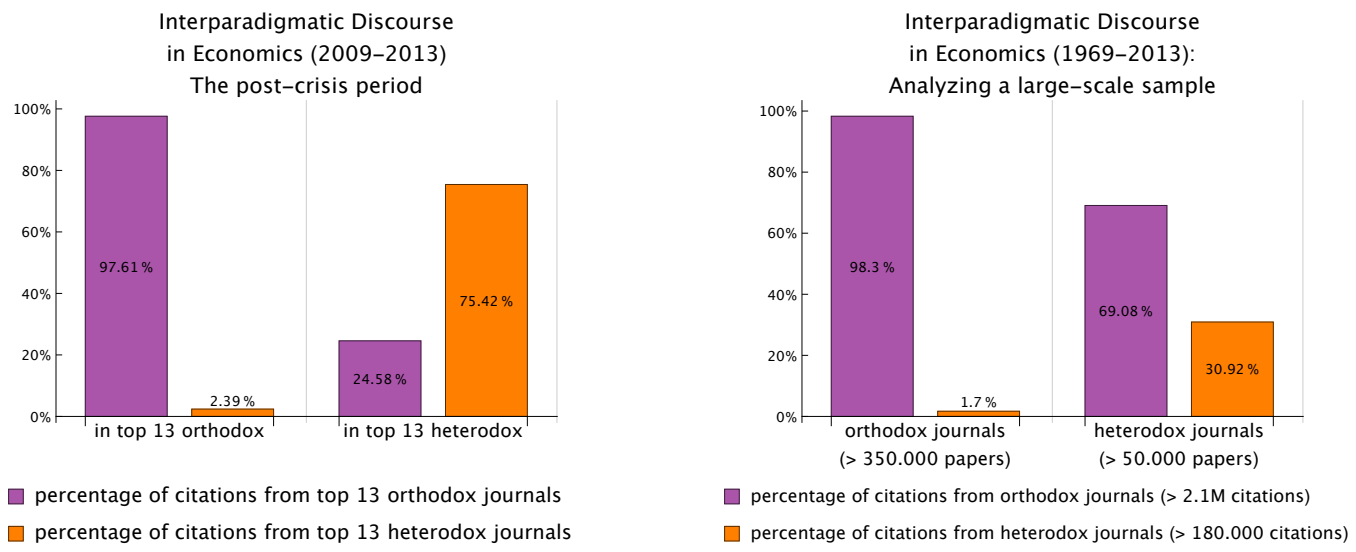

Figure 9: Diversity and the interaction pattern between economic mainstream and heterodox journals. Top left: the discourse between a sample of top 13 orthodox and top 13 heterodox journals (1989-2008; taken from Dobusch \& Kapeller 2012b); Top right: replication with a corresponding control group (1989-2008; author's own calculation based on data from Clarivate Analytics). Bottom left: replication for the post-crisis period (2009-2013; author's own calculation based on data from Clarivate Analytics); Bottom right: Analysis of a largescale journal sample (1969-2013; taken from Aigner \& Glötzl, this issue ${ }^{14}$

By comparing these results to other recent findings on the 'insularity' of the economics discipline (Fourcade et al. 2015), one notices several similarities between an interdisciplinary and an intradisciplinary view on conceptual openness in economics. For once, we do not only find that economics is comparatively closed to outside disciplines, but also to theoretical outsiders within the discipline. For another, we observe that these theoretical outsiders do share close ties to other branches of the social sciences (e.g. Glötzl \& Aigner 2015), thereby not resembling the disciplinary isolation practiced by the economic mainstream. A possible, tentative conclusion to be drawn from this is that the interdisciplinary insularity of economics as diagnosed by Fourcade et al. (2015) or Gingras and Schinckus (2012; with respect to econophysics) is not primarily due the idiosyncracies and peculiarities of the subject matter in economics, but rather represents an outgrowth of the dominant economic approach which seems to a priori discount external inputs.

Qualitative examples for illustrating the above line of argument are easily found. One instance is provided by the 'Economics of Identity' - a stream of research based on a wellreceived paper by Akerlof \& Kranton (2000), which gathered well more than 800 citations in Web of Science, most of them from the field of economics. In this context, it is interesting to note that the conceptual core of 'identity' as introduced in economics - that people have ideas about who they are and try to conform to these ideas in their behavior - overlaps strongly with the meaning of identity as used by social psychologists since, at least, the 1950s. While Akerlof \& Kranton (2000) obviously import this idea into economics and thereby attract much interest within their profession, classic contributions on social identity in other fields, e.g. Tajfel (1974) or Ashforth \& Mael (1989), remain largely neglected in the economic discourse, although they are widely cited in general. In sum, these two papers have more than 3,000 documented citations in Web of Science, where only 34 of those stem from economics $^{15}$. Hence, Akerlof \& Kranton (2000) have contributed significantly to increasing the prominence of the psychological concept of identity within economics. It, however, remains difficult to say, whether this increase in prominence is to be attributed to an increase in visibility or legitimacy. In the former interpretation, 'economists read narrowly' and

\footnotetext{
${ }^{14}$ We are grateful to Ernest Aigner and Florentin Glötzl for providing the data necessary to perform this analysis.

${ }^{15}$ Citing articles from Web of Science Core Collection (accessed October 2018)
} 
Akerlof \& Kranton (2000) simply introduce economists to an hitherto unknown concept personal identity - that is in turn taken up for further investigation. In the latter interpretation, 'only economists do it right' and personal identity as a theoretical concept gains credibility and plausibility exactly because it is being taken up by well-known economists in a very respected outlet. While our results point towards the importance of both factors, visibility as well as legitimacy, it is remarkable that the integration of identity in the economics' discourse does not spill over to the extra-disciplinary origins of said concept.

Against this backdrop, the relative 'superiority' of economics in terms of citation-trade balances - as suggested by Wolfers (2010) - cannot only be explained by a higher quality of research outputs, but also by a higher degree of group-think and inward-looking behavior within the economics profession; an interpretation well in line with the average economists stance on the value and merit of extra-disciplinary contributions. Yet again, we find that the two ways of looking at and interpreting citation data lead us to very different implications.

\section{Conclusion}

Most scientometric studies up to now remain committed to a certain perspective - either cognitive or evaluative - which in turn frames our understanding of the relevant data and has a strong imprint on the interpretation of results and the lessons drawn from these outcomes. In this paper we use the peculiar case of economics as an example for illustrating the partially stark differences arising from these two different points of view.

We have shown how citation patterns in current economics systematically differ from patterns found in other disciplines and have thereby further substantiated past results regarding the peculiar disciplinary character of academic economics (e.g. Dobusch \& Kapeller 2009, Fourcade et al. 2015, Leijonhufvud 1973, Morgan 1988). We suggested explaining these differences with reference to specific characteristics of economics, namely that economics exhibits a more intense disciplinary stratification (leading to and reinforcing concentration of attention within economics), that economists show greater awareness for institutional incentives (leading to reactive citation behavior) and, finally, that economics is a contested discipline dominated by a single approach (leading to a lack of openness for external inputs).

These observations thereby do align well with core elements of the dominant theoretical approach in economics: in the standard textbook view, competition is objective and leads to superior results when compared to other modes of social organization - hence, a focus on top journals seems natural and legitimate. In the standard textbook view, deviations from instrumental rationality and a corresponding neglect of incentives are portrayed as somehow foolish behavior - hence, reactivity is framed as a rational response to given constraints. Finally, the standard textbook view suggests that scientific progress has, more or less, linear properties - hence, a single, dominant theoretical approach is not seen as a limitation for the field, but, quite on the contrary, as a signifier for the superior status of economics as compared to its neighboring disciplines.

While we found that the data does really lend some support to our main hypotheses, all of our findings can be subjected to different interpretations. Higher concentration of attention might be due to more precise instruments for detecting the quality of manuscripts before publication. What seems like reactivity might be emerging from an otherwise invisible shift in patterns of quality in the underlying literature. And openness and ignorance in economic thinking might simply reflect differences in quality located at the level of more fundamental ideas. Our main message in this regard is to think carefully about one's preconceptions on what citations really signify, because, as we have shown, these preconceptions eventually determine the implications drawn from seemingly innocent empirical outcomes and results. 
Finally, our work also points to several policy implications regarding the link between current practices in research evaluation and the development of the economic discipline. In line with earlier findings on the disciplines' 'contestedness' our results suggest that the incentives arising from imposing citations as the 'currency of our industry' (Coffman et al. 2017,3) not only bears the risk of marginalizing alternative theoretical approaches within the discipline. It also tends to hamper intellectual exchange of knowledge across its disciplinary borders. 


\section{References}

Abatemarco, Antonio, and Roberto Dell'Anno. 2012. "The Italian Reform of the academic recruitment system: an appraisal of ANVUR and CUN benchmarks for assessing candidates and commissioners." Rivista Italiana degli Economisti 3:441-480.

Aistleitner, Matthias, Jakob Kapeller, and Stefan Steinerberger. 2018. "The Power of Scientometrics and the Development of Economics." Journal of Economic Issues 52(3):816-834.

Akerlof, George A., and Rachel E. Kranton. 2000. "Economics and Identity.” The Quarterly Journal of Economics 115(3):715-753.

Arrow, Kenneth J., B. Douglas Bernheim, Martin S. Feldstein, Daniel L. McFadden, James M. Poterba, and Robert M. Solow. 2011. "100 Years of the American Economic Review: The Top 20 Articles." The American Economic Review 101(1):1-8.

Ashforth, Blake E., and Fred Mael. 1989. "Social Identity Theory and the Organization." The Academy of Management Review 14(1):20-39.

Attema, Arthur E., Werner B. F. Brouwer, and Job Van Exel. 2014. "Your Right Arm for a Publication in AER?" Economic Inquiry 52(1):495-502.

Backhouse, Roger E. 2005. "The Rise of Free Market Economics: Economists and the Role of the State since 1970." History of Political Economy 37(5):355-392.

Baghestanian, Sascha, and Sergey V. Popov. 2017. "Alma mat(t)er(s): Determinants of early career success in economics." Economcis Working Papers 17-02, Queens Management School, Queen's University Belfast.

Bauman, Yoram, and Elaina Rose. 2011. "Selection or indoctrination: Why do economics students donate less than the rest?" Journal of Economic Behavior \& Organization 79(3):318-327.

Bayer, Amanda, and Cecilia E. Rouse. 2016. "Diversity in the Economics Profession: A New Attack on an Old Problem." Journal of Economic Perspectives 30(4):221-242.

Beker, Victor, A. 2010. "On the Economic Crisis and the Crisis of Economics." Economics Discussion Papers No.2010-18. Kiel Institute for the World Economy. http://www.economics-ejournal.org/economics/discussionpapers/2010-18

Bloch, Harry. 2010. "Research Evaluation Down Under: An Outsider's View from the Inside of the Australian Approach." The American Journal of Economics and Sociology 69(5):1530-1552.

Braun, Tibor, Carl T. Bergstrom, Bruno S. Frey, Margit Osterloh, Jevin D. West, David Pendlebury, and Jennifer Rohn. 2010. "How to improve the use of metrics." Nature 465(7300):870-872.

Card, David, and Stefano DellaVigna. 2013. "Nine facts about top journals in economics." Journal of Economic Literature 51(1):144-161.

Coffman, Lucas C., Muriel Niederle, and Alistair J. Wilson. 2017. "A Proposal to Organize and Promote Replications." The American Economic Review 107(5):41-45.

Colussi, Tommaso. 2018. "Social Ties in Academia: A Friend is a Treasure." The Review of Economics and Statistics 100(1):45-50.

Corsi, Marcella, Carlo D'Ippoliti, and Federico Lucidi. 2010. "Pluralism at Risk? Heterodox Economic Approaches and the Evaluation of Economic Research in Italy." The American Journal of Economics and Sociology 69(5):1495-1529. 
D'Ippoliti, Carlo. 2018. “'Many-Citedness': Citations Measure More Than Just Scientific Impact”. INET Working Paper No. 57.

https://www.ineteconomics.org/uploads/papers/WP_57-DIppoliti-revised.pdf.

De Solla Price, Derek J. 1965. “Networks of Scientific Papers.” Science 149(3683):510-515.

Diamond, Arthur M. 1989. "The Core Journals of Economics." Current Contents 1:4-11.

Dobusch, Leonhard, and Jakob Kapeller. 2009. "Why is Economics not an Evolutionary Science? New Answers to Veblen's old Question." Journal of Economic Issues 43(4):867-898.

Dobusch, Leonhard, and Jakob Kapeller. 2012a. "Heterodox United vs. Mainstream city? Sketching a framework for interested pluralism in economics." Journal of Economic Issues 46(4):1035-1057.

Dobusch, Leonhard, and Jakob Kapeller. 2012b. "A guide to paradigmatic Selfmarginalization - Lessons for Post-Keynesian Economists." Review of Political Economy 24(3):469-487.

Edwards, Marc A., and Siddhartha Roy. 2017. "Academic Research in the $21^{\text {st }}$ Century: Maintaining Scientific Integrity in a Climate of Perverse Incentives and Hypercompetition.” Environmental Engineering Science 34(1):51-61.

Espeland, Wendy. N, and Michael Sauder. 2007. "Rankings and Reactivity: How Public Measures Recreate Social Worlds." American Journal of Sociology 113(1):1-40.

Etzioni, Amitai. 2015. "The Moral Effects of Economic Teaching.” Sociological Forum 30(1):228-233.

Ferraro, Fabrizio, Jeffrey Pfeffer, and Robert I. Sutton. 2005. "Economics language and assumptions: How theories can become self-fulfilling." Academy of Management Review 30(1):8-24.

Fourcade, Marion, Etienne Ollion, and Yann Algan. 2015. "The superiority of economists." Journal of Economic Perspectives 29(1):89-114.

Frank, Robert H., Thomas Gilovich, and Dennis T. Regan. 1993. "Does Studying Economics Inhibit Cooperation?" Journal of Economic Perspectives 7(2):159-171.

Frank, Robert H., Thomas Gilovich, and Dennis T. Regan. 1996. "Do Economists Make Bad Citizens?” Journal of Economic Perspectives 10(1):187-192.

Frey, Bruno S., Werner W. Pommerehne, and Beat Gygi. 1993. "Economics Indoctrination or Selection? Some Empirical Results." The Journal of Economic Education 24(3):271281.

Fusfeld, Daniel R. 1956. "The Program of the American Economic Association Meetings.” The American Economic Review 46(4):642-644.

Ghoshal, Sumantra. 2005. "Bad Management Theories Are Destroying Good Management Practices." Academy of Management Learning \& Education 4(1):75-91.

Gingras Yves, and Christopher Schinckus. 2012. "The Institutionalization of Econophysics in the Shadow of Physics." Journal of the History of Economic Thought 34(1):109-130.

Graupe, Silja. 2016. "Der erstarrte Blick. Eine erkenntnistheoretische Kritik der Standardlehrbücher der Volkswirtschaftslehre." In Wirtschaft neu denken. Blinde Flecken der Lehrbuchökonomie, edited by Till van Treeck, and Janina Urban, 18-29. Berlin: iRights.Media. 
Graves, Philip E., James R. Marchand, and Randall Thompson. 1982. "Economics Departmental Rankings: Research Incentives, Constraints, and Efficiency." The American Economic Review 72(5):1131-1141.

Glötzl, Florentin, and Ernest Aigner. 2015. "Pluralism in the Market of Science? A citation network analysis of economic research at universities in Vienna." Ecological Economic Papers 5. WU Vienna University of Economics and Business, Vienna

Hall, Peter. A. 1989. The Political Power of Economic Ideas: Keynesianism Across Nations. Princeton: Princeton University Press.

Hamermesh, Daniel S. 2018. 'Citations in Economics: Measurement, Uses, and Impacts.' Journal of Economic Literature 56, no. 1: 115-156.

Han, Shin-Kap. 2003. "Tribal regimes in academia: a comparative analysis of market structure across disciplines." Social Networks 25(3):251-280.

Haucap, Justus, and Johannes Muck. 2015. "What Drives the Relevance and Reputation of Economics Journals? An Update from a Survey among Economists." Scientometrics 103(3):849-877.

Heckman, James J., and Sidharth Moktan. 2018. "Publishing and Promotion in Economics. The Tyranny of the Top Five." Institute for New Economic Thinking, Working Paper $82 \mathrm{https}$ ://www.ineteconomics.org/research/research-papers/publishing-and-promotionin-economics-the-tyranny-of-the-top-five ; NBER Working Paper No. 25093.

Hodgson, Geoffrey M., and Harry Rothman. 1999. "The editors and authors of economics journals: a case of institutional oligopoly?” Economic Journal 109(453):F165-F186.

Høyland, Bjorn, Kalle Moene, and Fredrik Willumsen. 2008. "Be careful when Doing Business." Report commissioned by the Norwegian Ministry of Foreign Affairs, Oslo.

Kapeller, Jakob. 2010. "Citation Metrics: Serious drawbacks, perverse incentives and strategic options for heterodox economics." American Journal of Economics and Sociology 69(5):1376-1408.

Kalaitzidakis, Pantelis, Theofanis, P. Mamuneas, and Thanasis Stengos. 2011. "An Updated Ranking of Academic Journals in Economics." Canadian Journal of Economics 44(4):1525-1538.

Kim, E. Han, Adair Morse, and Luigi Zingales. 2006. "What Has Mattered to Economics Since 1970.” Journal of Economic Perspectives 20(4):189-202.

King, John E. 2003. A History of Post-Keynesian Economics since 1936. Cheltenham: Edward Elgar.

King, John E. 2013. "A case for pluralism in economics". The Economic and Labour Relations Review 24(1):17-31.

Kuhn, Thomas S. 1962. The Structure of Scientific Revolutions. Chicago: University of Chicago Press.

Laband, David N. 2013. "On the use and abuse of economics journal rankings." The Economic Journal 123(570):F223-F254.

Lariviére, Vincent, and Yves Gingras. 2010. "The Impact Factor's Matthew Effect: A Natural Experiment in Bibliometrics." Journal of the American Society for Information Science and Technology 61(2):424-427.

Larivière, Vincent, Yves Gingras, and Éric Archambault. 2009. "The decline in the concentration of citations, 1900-2007." Journal of the Association for Information Science and Technology 60(4):858-862. 
Lazear, Edward P. 2000. “Economic Imperialism.” Quarterly Journal of Economics 115(1):99-146.

Lee, Frederic S. 2007. "The Research Assessment Exercise, the state and the dominance of mainstream economics in British universities." Cambridge Journal of Economics 31(2):309-325.

Lee, Frederic S., Bruce C. Cronin, Scott McConnell, and Erik Dean. 2010. "Research Quality Rankings of Heterodox Economic Journals in a Contested Discipline." The American Journal of Economics and Sociology 69(5):1409-1452.

Lee, Frederic S., and Wolfram Elsner. 2011. Evaluating Economic Research in a Contested Discipline: Ranking, Pluralism, and the Future of Heterodox Economics. John Wiley \& Sons.

Leijonhufvud, Axel. 1973. "Life among the Econ.” Economic Inquiry 11(3):327-337.

Liebowitz, Stan J., and John P. Palmer. 1984. "Assessing the Relative Impacts of Economics Journals.” Journal of Economic Literature 22(1):77-88.

Mcdonald, Stuart, and Jacqueline Kam. 2007. "Ring a Ring o' Roses: Quality Journals and Gamesmanship in Management Studies." Journal of Management Studies 44(4):640_ 655.

Medoff, Marshall H. 2006. "Evidence of a Harvard and Chicago Matthew Effect." Journal of Economic Methodology 13(4):485-506.

Merton, Robert K. 1968. “The Matthew Effect in Science.” Science 159(3810):56-63.

Mingers, John, and Loet Leydesdorff. 2015. "A review of theory and practice in scientometrics." European Journal of Operational Research 246(1):1-19.

Mirowski, Philip. 1989. More heat than light. Cambridge University Press.

Moed, Henk F., Lisa Colledge, Jan Reedijk, Felix Moya-Anegon, Vincente Guerrero-Bote, Andrew Plume, and Mayur Amin. 2012. "Citation-based metrics are appropriate tools in journal assessment provided that they are accurate and used in an informed way." Scientometrics 92(2):367-376.

Morgan, Theodore. 1988. "Theory versus Empiricism in Academic Economics: Update and Comparisons." Journal of Economic Perspectives 2(4):159-164.

Necker, Sarah. 2014. "Scientific Misbehavior in Economics." Research Policy 43(10): 17471759.

Pieters, Rik, and Hans Baumgartner. 2002. "Who Talks to Whom? Intra- and Interdisciplinary Communication of Economics Journals." Journal of Economic Literature 40(2):483509.

Rafols, Ismael, Loet Leydesdorff, Alice O'Hare, Paul Nightingale, and Andy Stirling. 2012. "How journal rankings can suppress interdisciplinary research: A comparison between Innovation Studies and Business \& Management.” Research Policy 41(7):1262-1282.

Rip, Arie, and Jean Pierre Courtial. 1984. "Co-Words Maps in Biotechnology: An Example of Cognitive Scientometrics.” Scientometrics 6(6):381-400.

Samuelson, Paul A. 1972. "Maximum Principles in Analytical Economics." The American Economic Review 62(3):249-262.

Skousen, Mark. 1997. “The Perseverance of Paul Samuelson's Economics.” Journal of Economic Perspectives 11(2):137-152. 
Stern, David I. 2013. "Uncertainty Measures for Economics Journal Impact Factors.” Journal of Economic Literature 51(1):173-189.

Tajfel, Henri. 1974. "Social identity and intergroup behaviour." Social Science Information 13(2):65-93.

Torgler, Benno, and Piatti, Marco. 2013. A century of American Economic Review. London: Palgrave.

Tsay, Ming-Yueh. 2009. "An analysis and comparison of scientometric data between journals of physics, chemistry and engineering." Scientometrics 78(2):279-293.

Wallace, Matthew L., Vincent Larivière, and Yves Gingras. 2012. "A Small World of Citations? The Influence of Collaboration Networks on Citation Practices." PLoS ONE 7(3):e33339.

Wilhite, Allen W., and Eric A. Fong. 2012. "Coercive Citation in Academic Publishing." Science 335(6068):542-543.

Willmott, Hugh. 2011. "Journal list fetishism and the perversion of scholarship: reactivity and the ABS list." Organization 18(4):429-442.

Wolfers, Justin. 2010. Interview in Region Focus, Second Quarter 2010, Federal Reserve Bank of Richmond, 13 March 2017

https://www.richmondfed.org/publications/research/econ_focus/2010/q2/full_interview.

Wu, Stephen. 2007. "Recent publishing trends at the AER, JPE and QJE." Applied Economics Letters 14(1):59-63.

Yezer, Anthony M., Robert S. Goldfarb, and Paul J. Poppen. 1996. "Does Studying Economics Discourage Cooperation? Watch What We Do, Not What We Say or How We Play." Journal of Economic Perspectives 10(1):177-186.

Zimmermann, Christian. 2013. “Academic Rankings with RePEc.” Econometrics 1:249-280. 